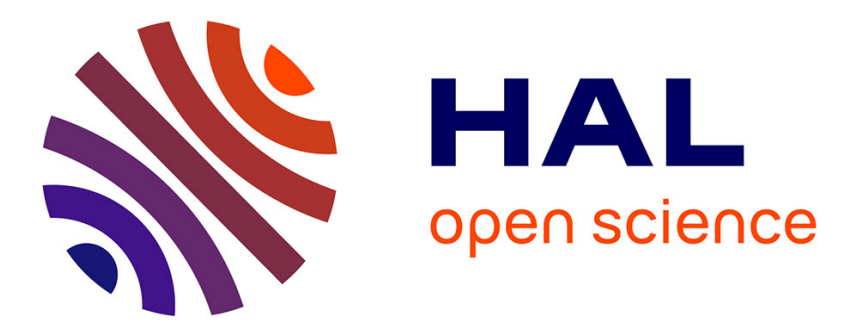

\title{
Determination of aliphatic hydrocarbons in urban runoff samples from the "Le Marais" experimental catchment in Paris centre
}

Régis Moilleron, Ana Gonzalez, Ghassan Chebbo, Daniel R. Thevenot

\section{To cite this version:}

Régis Moilleron, Ana Gonzalez, Ghassan Chebbo, Daniel R. Thevenot. Determination of aliphatic hydrocarbons in urban runoff samples from the "Le Marais" experimental catchment in Paris centre. Water Research, 2002, 36 (5), pp.1275 - 1285. 10.1016/S0043-1354(01)00322-0 . hal-00711801

\section{HAL Id: hal-00711801 \\ https://hal-enpc.archives-ouvertes.fr/hal-00711801}

Submitted on 27 Nov 2014

HAL is a multi-disciplinary open access archive for the deposit and dissemination of scientific research documents, whether they are published or not. The documents may come from teaching and research institutions in France or abroad, or from public or private research centers.
L'archive ouverte pluridisciplinaire HAL, est destinée au dépôt et à la diffusion de documents scientifiques de niveau recherche, publiés ou non, émanant des établissements d'enseignement et de recherche français ou étrangers, des laboratoires publics ou privés.

\section{(c)(1)}

Distributed under a Creative Commons Attribution| 4.0 International License 


\title{
Determination of aliphatic hydrocarbons in urban runoff samples from the "Le Marais" experimental catchment in Paris centre
}

\author{
Régis Moilleron ${ }^{\mathrm{a}, *}$, Ana Gonzalez ${ }^{\mathrm{a}}$, Ghassan Chebbo ${ }^{\mathrm{b}}$, Daniel R. Thévenot ${ }^{\mathrm{a}}$ \\ ${ }^{a}$ Cereve, Faculté de Sciences et de Technologie, Université Paris XII-Val de Marne, 61 Avenue du Général de Gaulle, \\ 94010 Créteil Cedex, France \\ ${ }^{\mathrm{b}}$ Cereve, Ecole Nationale des Ponts et Chaussées, Cité Descartes, 6-8 Avenue Blaise Pascal, 77455 Marne La Vallée Cedex 2, France
}

Received 15 December 2000; received in revised form 7 June 2001; accepted 18 June 2001

\begin{abstract}
Aliphatic hydrocarbons were assessed in runoff and waste waters from an urban catchment located in Paris. Runoff were sampled from different types of urban surfaces (11 roofs representing four different covering materials, two courtyards and six streets). Waste water samples were collected at the catchment outlet during dry and wet weather periods as well. This paper gives an overview of the results on the concentration and distribution points of view for both the particulate and the dissolved phases. Results were discussed on the basis of the median. Accordingly, the temporal variability was taken into account. Thus, the concentration medians ranged from 345 to 827, from 297 to 790 , and from 393 to $1359 \mu \mathrm{g} \mathrm{L}^{-1}$ in the roof, courtyard and street samples, respectively. The levels found at the catchment outlet during dry and wet weather periods were of the same order of magnitude, i.e. $700 \mu \mathrm{g} \mathrm{L}^{-1}$. The particulate phase represented $85 \%$ of the total aliphatic hydrocarbon content whatever the sample. (C) 2002 Elsevier Science Ltd. All rights reserved.
\end{abstract}

Keywords: Aliphatic hydrocarbons; Urban surfaces; Urban runoff; Combined sewer; Experimental catchment

\section{Introduction}

Growing urbanisation along with the increase of anthropic activities in the last few decades have turned urban runoff into a major problem both from the point of view of the flow quantities and its quality. The importance of urban storm water runoff pollution loads and their acute impact on receiving waters (river, lake or sea) have been largely proved [1-4]. Today, the reduction of urban storm water pollution has become a major concern for many municipalities both in order to improve the quality of the receiving water bodies and in order to meet the new European regulations. However, the elaboration of urban storm water manage-

\footnotetext{
*Corresponding author. Tel.: +33-1-4517-1622; fax: +33-14517-1627.

E-mail address: moilleron@univ-paris12.fr (R. Moilleron).
}

ment strategies requires improved knowledge on the characteristics, the origins and the transport of pollution during a rain event in different sites within an urban catchment. The assessment of these three points was the aim of an important research programme launched by the CEREVE (Centre d'Enseignement et de Recherche sur l'Eau, la Ville et l'Environnement: a Water Research Centre) in 1994, entitled "Production and transport of wet weather pollution in urban catchments". This research was performed on an experimental urban catchment, located in the "Le Marais" district in central Paris, fully equipped in order to follow up the quality of wet weather flows during a rain event. Many parameters have been studied such as suspended solids (SS), volatile solids, chemical oxygen demand (COD), biochemical oxygen demand (BOD), heavy metals and hydrocarbons. This paper states the results obtained for the measurement of aliphatic hydrocarbons present both in 
the particulate and in the dissolved phases and gives the levels found in the different types of urban runoff from roofs, courtyards and streets, as well as in waste water samples collected at the catchment outlet during dry and wet weather periods, that took place in 1996 and 1997 in Paris. The hydrocarbon pattern was used in an attempt to investigate sources and the fate of aliphatic hydrocarbons within the "Le Marais" urban catchment. A comparison was carried out between the results of this study and the polycyclic aromatic hydrocarbon (PAH) contents, which were previously investigated [5].

\section{Materials and methods}

\subsection{Sampling sites}

This research was conducted on a 42 ha experimental urban catchment area, the "Le Marais" catchment, situated in the historical centre of Paris. It is a densely populated residential area (295 inhabitants per hectare) with small businesses and almost bereft of industrial activities. The catchment area can be divided into roof surfaces $(54.4 \%)$, streets $(22.4 \%)$, courtyards (mainly impervious), public squares and gardens (23.2\%). Around $90 \%$ of the catchment area is impervious, which is typical of a dense town centre. The sewer network is combined, ramified and completely manentry, with non-selective gullies for street runoff drainage. It includes three ovoid trunks with sidewalks, with a total length of $1.8 \mathrm{~km}$, and around 50 egg-shaped collectors with a total length of $5.8 \mathrm{~km}$. The slope of the main trunks is rather slack (less then $0.1 \%$ ) whereas the collectors have higher slopes with an average of $0.8 \%$.
Important levels of sediments $(15 \pm 60 \mathrm{~cm})$ are found in the upper part of the trunk sewers, whereas there are very little sediment in the collectors.

In order to characterise and quantify the pollution from roof, street and courtyard runoff, several sampling sites representative of the different types of land use were chosen as shown in Fig. 1. The roof runoff was sampled from 11 roofs, representative of roof covering materials in the centre of Paris, i.e. interlocking clay tiles (ICT), flat clay tiles $(70 \%)+$ zinc sheet $(\mathrm{FCT})$, zinc sheets (ZNT) and slate (ST). Mean samples were taken in the roof gutters, during rain events, and collected in $100 \mathrm{~L}$ containers. Samples from two courtyards were collected with automatic samplers located inside the courtyard gullies. The courtyards were either paved with cobble stones (PAVC) or concrete and planted with trees (CONC). Street runoff from six different streets was collected in three gullies, Duval (DUV), Vieille Du Temple (VDT) and Turenne (TUR). The characteristics of the streets are given in Table 1. Samples were collected at the catchment outlet during wet (COWW) and dry (CODW) weather periods. A full description of the monitoring equipment is given elsewhere [6].

\subsection{Extraction and purification}

All solvents were purified by distillation before use. To avoid contamination, the vessels used for sampling and analysis were treated as follows: the glassware was cleaned with 5\% Decon detergent (Prolabo), then rinsed with purified water (Milli-Ro 5 Plus, Millipore), and heated in an oven at $450^{\circ} \mathrm{C}$ for $2 \mathrm{~h}$ in order to eliminate any trace of organic matter.

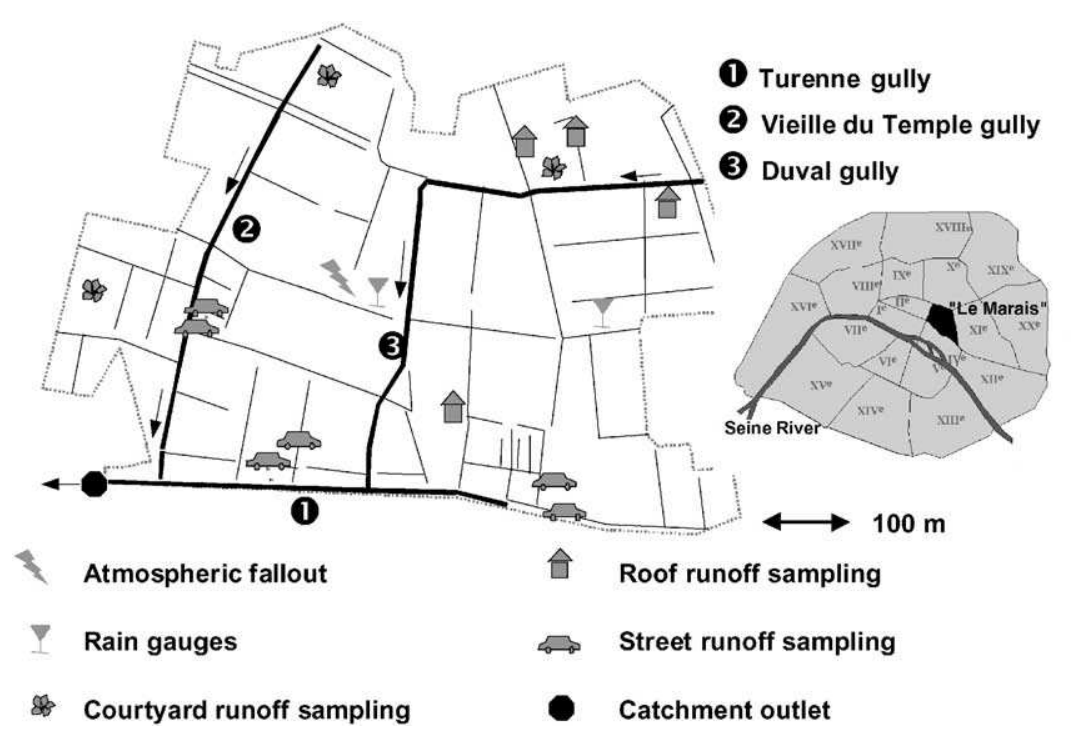

Fig. 1. Sampling equipment at the "Le Marais" experimental urban catchment. 
Table 1

Characteristics of the streets sampled on the "Le Marais" experimental urban catchment

\begin{tabular}{|c|c|c|c|c|c|c|c|}
\hline Gully & Street name & Lanes & $\begin{array}{l}\text { Parking } \\
\text { places }\end{array}$ & Traffic & Asphalt & Business & $\begin{array}{l}\text { Drainage } \\
\text { area }\left(\mathrm{m}^{2}\right)\end{array}$ \\
\hline \multirow[t]{2}{*}{ Turenne } & Saint Antoine & 3 & No & Heavy & Good & Numerous & 1017 \\
\hline & Turenne & 2 & Yes & Medium & Good & Few & 1700 \\
\hline \multirow[t]{2}{*}{ Duval } & Duval & 1 & Yes & Low & Poor & Few & 160 \\
\hline & Roi de Sicile & 1 & Yes & Low & Good & Few & 284 \\
\hline \multirow[t]{2}{*}{ Vielle du Temple } & Marché Blanc Manteaux & 1 & No & Low & Good & No & 195 \\
\hline & Rosiers & 1 & No & Medium & Good & Numerous & 186 \\
\hline
\end{tabular}

For runoff samples, an aliquot, typically $1 \mathrm{~L}$, was filtered by using a succession of pre-combusted and preextracted filters, from $2.7 \mu \mathrm{m}(\mathrm{GF} / \mathrm{F}$, Whatman) to $0.45 \mu \mathrm{m}$ (Millipore), in an all-glass filtration unit in order to separate dissolved and particulate phases. Particulate matter was dried to a constant weight at $40^{\circ} \mathrm{C}$. Before the extraction step of the procedure, internal perdeuterated standards were added in both phases, i.e. dodecane $\left(\mathrm{C}_{12}\right.$ or $\left.\mathrm{D}_{26}\right)$, tetracosane $\left(\mathrm{C}_{24}\right.$ or $\left.\mathrm{D}_{50}\right)$, and triacontane $\left(\mathrm{C}_{30}\right.$ or $\left.\mathrm{D}_{62}\right)$.

\subsubsection{Dissolved aliphatic hydrocarbon extraction}

The filtered samples were extracted by simple liquidliquid extraction in a separation funnel using four successive $30 \mathrm{~mL}$ additions of methylene chloride (Merck). Before the last extraction, sample $\mathrm{pH}$ was adjusted to 2 using concentrated $\mathrm{H}_{2} \mathrm{SO}_{4}$ (Merck). Each of the four portions was shaken with the filtrate sample for $10 \mathrm{~min}$. The extracts were then combined, dried using $\mathrm{CaCl}_{2}$ (Prolabo) and concentrated to ca $5 \mathrm{~mL}$ using a rotary evaporator at room temperature under vacuum. This fraction was further evaporated to dryness under nitrogen flux (N5.0, Linde Gaz). Then $500 \mu \mathrm{L}$ of hexane (Merck) was added. This aliquot was fractionated into two fractions on a chromatographic column of $2 \mathrm{~g}$ of silica gel (Aldrich, $5.5 \mathrm{~mm} \mathrm{ID} \times 30 \mathrm{~cm}$ in length), by eluting with (i) $4 \mathrm{~mL}$ hexane and (ii) $6 \mathrm{~mL}$ methylene chloride-hexane $(80 / 20, \mathrm{v} / \mathrm{v})$, respectively. Aliphatic hydrocarbons were eluted with hexane (F1) and PAHs with the methylene chloride-hexane mixture (F2). Silica gel (Aldrich, 70-230 mesh, 60 $)$ ) was preactivated at $450^{\circ} \mathrm{C}$ for $2 \mathrm{~h}$ and stored at $100^{\circ} \mathrm{C}$ prior to use. $\mathrm{F} 1$ and F2 were evaporated to ca $50-100 \mu \mathrm{L}$ under nitrogen flux before quantification.

\subsubsection{Particulate aliphatic hydrocarbon extraction}

Dried particulate matter was Soxhlet extracted for $24 \mathrm{~h}$ with a methylene chloride-methanol mixture $(80 / 20$, $\mathrm{v} / \mathrm{v})$. The extract was then concentrated to dryness under nitrogen flux as previously described. Then $500 \mu \mathrm{L}$ of hexane was added. This aliquot was eluted on a chromatographic column $(5.5 \mathrm{~mm}$ ID $\times 30 \mathrm{~cm}$ in length), composed at the bottom of a layer of $500 \mathrm{mg}$ of activated copper (Aldrich, powder, 40 mesh, 99.5\%) in order to desulphurise the sample and, at the top, a layer of $2 \mathrm{~g}$ of silica gel. Aliphatic hydrocarbons were eluted with $4 \mathrm{~mL}$ of hexane (F1) and PAHs with $6 \mathrm{~mL}$ of a methylene chloride-hexane mixture $(80 / 20, \mathrm{v} / \mathrm{v})(\mathrm{F} 2)$. F1 and F2 were evaporated to ca $50-100 \mu \mathrm{L}$ under nitrogen flux prior to quantification. Copper was activated with $\mathrm{HCl}(7 \mathrm{~N})$, then washed with distilled water, acetone and hexane. Activated copper was kept in hexane at $4^{\circ} \mathrm{C}$ before use.

\subsection{Chromatographic analysis}

Aliphatic hydrocarbons were determined by GC-MS (GCD 1800 A, Hewlett Packard) using a PONA fused silica capillary column, $50 \mathrm{~m} \times 0.20 \mathrm{~mm}$ ID $\times 0.1 \mu \mathrm{m}$ film thickness (Hewlett Packard). The carrier gas was hydrogen at $1.0 \mathrm{~mL} \mathrm{~min}^{-1}$. The injector temperature was set to $300^{\circ} \mathrm{C}$ and $1 \mu \mathrm{L}$ was injected. For aliphatic hydrocarbons, the column temperature was programmed from $70^{\circ} \mathrm{C}$ to $300^{\circ} \mathrm{C}$, at $5^{\circ} \mathrm{C} \mathrm{min}^{-1}$, and held for $24 \mathrm{~min}$. System control and data acquisition were monitored by a HP ChemStation software. The GCD apparatus was operated in the scan mode. The identification was completed by using an NIST database (NIST/EPA/NIH Mass Spectral Database, Hewlett Packard). The whole analytical procedure was validated using certified samples such as marine sediment SRM1941a (NIST), which is certified for its polycyclic aromatic hydrocarbon content, whereas the aliphatic contents are given as non-certified, i.e. indicative [7].

\section{Results and discussion}

While some authors present mean values when dealing with hydrocarbon amounts in urban runoff, we shall discuss our results on the basis of the median, lower and upper deciles, respectively, d50, d10 and d90. Accordingly, the temporal variability of the results will be taken into account. 
Table 2

Rain event characterisation (for the 19 assessed rain events)

\begin{tabular}{lcccc}
\hline$n=19$ & $\begin{array}{l}\text { Mean intensity } \\
\left(\mathrm{mm} \mathrm{h}^{-1}\right)\end{array}$ & $\begin{array}{l}\text { Total height } \\
(\mathrm{mm})\end{array}$ & $\begin{array}{l}\text { Duration } \\
(\mathrm{min})\end{array}$ & $\begin{array}{l}\text { Dry weather period } \\
\text { before the last storm (days) }\end{array}$ \\
\hline $\mathrm{d} 10$ & 1.6 & 2.9 & 40 & 0.7 \\
$\mathrm{~d} 50$ & 3.7 & 8.6 & 99 & 3.5 \\
$\mathrm{~d} 90$ & 16.8 & 18.3 & 294 & 12.5 \\
$\min$ & 1.1 & 3.0 & 29 & 0.1 \\
$\max$ & 26.7 & 21.6 & 416 & 50.1 \\
\hline
\end{tabular}

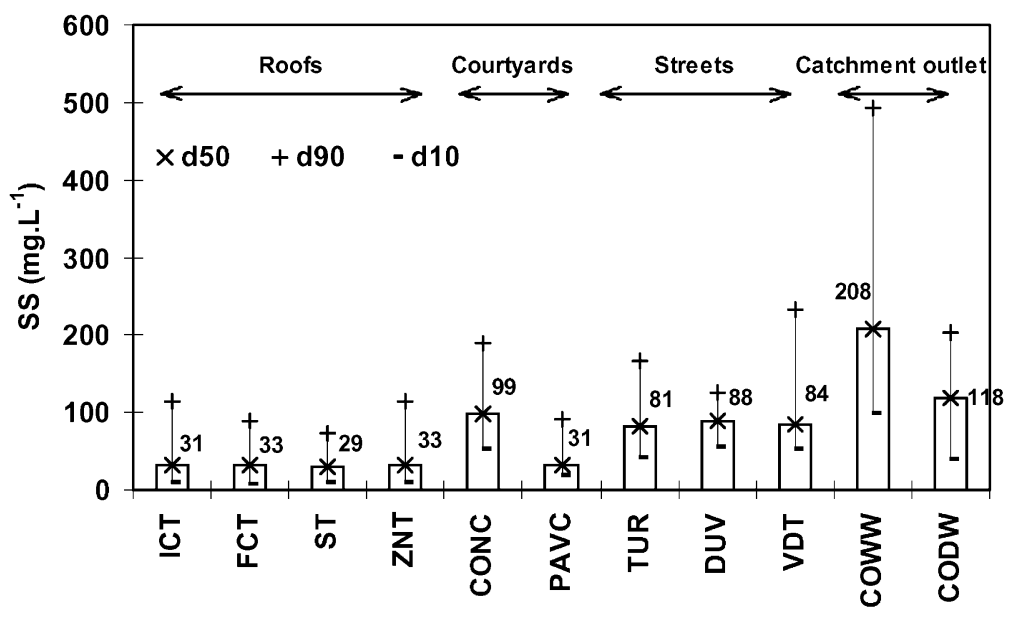

Fig. 2. Suspended solid (SS) concentration $\left(\mathrm{mg} \mathrm{L}^{-1}\right)$ in the samples from the "Le Marais" experimental urban catchment (figures give the median value).

\subsection{Characteristics of the rain events}

Nineteen rain events were sampled spanning two years, 1996 and 1997. The rain events were of various characteristics as shown in Table 2. A rain event was defined as a rainfall of a total height of at least $1 \mathrm{~mm}$ and separated one from another by a dry weather period of at least $30 \mathrm{~min}$ [6]. The storm duration varied from a few minutes $(29 \mathrm{~min})$ to several hours $(6 \mathrm{~h} 56 \mathrm{~min})$, and the total amount of rainfall varied from 3 to $21.6 \mathrm{~mm}$. Thus a wide range of rain events was covered. However, for technical reasons, it occurred that the runoff could not be sampled on all sites for each storm.

\subsection{Suspended solid contents}

The measurement of the SS contents in urban runoff is of major concern with respect to the transport of anthropogenic pollutants, since pollutants are dominantly bound to particles [8-10]. On the "Le Marais" catchment, temporal variability was noticed for runoff and waste waters at the sewer outlet; nevertheless, the amplitude between $\mathrm{d} 10$ and $\mathrm{d} 90$ was less than one order of magnitude (Fig. 2).

As for roof surfaces, the SS sources may be classified as point sources (e.g. a chimney) or non-point sources (pollution is emitted from multiple small sources spread over a considerable area). Therefore, the following emissions of fallout are of importance: vehicle exhausts, industrial or domestic chimney emissions, including incinerators. These emissions return to the urban surfaces after a rain, snow or fog event (wet deposition) or as gases and particulate (dry deposition). The contribution of each source to local pollution varies according to the type and number of local industries, density of road transport and local weather conditions. At the scale of the "Le Marais" catchment, which is a residential area, there are no local industrial sources. The main sources of particle loading are either the deposition during dry weather periods of particles being transported over more or less long distances, including polluted particles from industrial plants, or wet deposition along with the erosion of urban furniture. Our data showed that dissolution of the roof covering material was negligible, since the SS contents remained constant, 
i.e. $30 \mathrm{mg} \mathrm{L}^{-1}$, whatever the covering material (Fig. 2). This point is in contradiction with the results of Förster [11], who stated that the differences he observed for $\mathrm{pH}$ and the conductivity between the different investigated roofs (concrete tiles, fibrous cement, pantiles, zinc sheet and tar felt) were due to the influence of the roof material itself rather than dissolution of deposited atmospheric fallout, excepted at the beginning of the rain when both phenomena coexisted. The differences in the sampling procedure-Förster [11] sampled in order to get runoff profiles, whereas we worked on mean samples taken in the roof gutters, during rain eventsdo not explain the specific trends of both works. Therefore, it can be assumed that atmospheric fallout, the predominant pathway of particle loading to roofs, is homogeneous all over the "Le Marais" catchment due to its small size.

For street surfaces, apart from the atmospheric deposition, the following emissions are of particular importance as particle loading: (i) engine exhausts, (ii) wear, leakage, and spill products from vehicles as well as (iii) wear products from road pavements. Further, particles accumulated on the street surfaces can be removed by traffic before being transported in suspensions or solutions. During wet weather periods, runoff is the major removal mechanism of road particles. Although the streets were significantly different in terms of traffic density or roughness (Table 1), our results showed no differences from one street to another for SS contents. The SS medians ranged around $85 \mathrm{mg} \mathrm{L}^{-1}$ (Fig. 2). Thus, no spatial variability was observed for roof and street samples. SS contents were not affected by the surface characteristics of roofs and streets.

On the contrary, a surface effect was observed in the courtyards; there was a significant 3 fold increase in the SS amount for the concrete courtyard when compared to the paved one, i.e. $99-31 \mathrm{mg} \mathrm{L}^{-1}$, respectively. It is likely that the roughness of the paved courtyard led to a decrease of the SS contents by trapping some particles in bumps, as opposed to the concrete courtyard, which was smoother, leading to a better particle recovering. At the catchment outlet, the SS content during the dry weather periods, which represented the background level, was around $118 \mathrm{mg} \mathrm{L}^{-1}$. At the scale of a rain event, the SS concentration reached $208 \mathrm{mg} \mathrm{L}^{-1}$, a value higher than any runoff SS content entering the sewer. This was typical of an erosion of the sewer deposit that occurred during storm.

\subsection{Total aliphatic hydrocarbon contents in the "Le Marais" catchment}

More than 20 resolved hydrocarbons or $n$-alkanes, i.e. from $n-\mathrm{C}_{10}$ to $n-\mathrm{C}_{40}$, have been identified in the different types of samples within the "Le Marais" urban catchment, whatever the phase (dissolved or particulate) as shown in Fig. 3. This figure represents typical chromatograms of the aliphatic fraction (F1) of various runoff samples. In addition, pristane $(\mathrm{Pr})$ and phytane $(\mathrm{Ph})$, two isoprenoids, were also regularly observed. These results were similar to those reported previously, since urban samples were characterised by the presence of resolved aliphatic hydrocarbons from $n-\mathrm{C}_{12}$ to $n-\mathrm{C}_{34}$ [10], from $n-\mathrm{C}_{10}$ to $n-\mathrm{C}_{32}$ [12] and from $n-\mathrm{C}_{15}$ to $n-\mathrm{C}_{38}$ [13]. The particulate fraction, when present, was characterised by the presence of a substantial unresolved portion, i.e., the "hump" under the $n$-alkanes on a chromatographic trace as shown in Fig. 3. Several studies using gas chromatographic analysis of hydrocarbons show the same pattern, called unresolved complex mixture (UCM). The UCM is a common feature of the gas chromatograms of crude oils and certain refined products such as lubricating oils, and it is especially marked for weathered and biodegraded oils $[14,15]$. The UCM is a complex mixture, extremely resistant to biodegradation, composed of many structurally complex isomers and homologous of branched and cyclic alkanes [13].

Table 3 reports the concentrations of the total aliphatic hydrocarbons (TAHs) in the different samples collected during this study. The term "total aliphatic hydrocarbon (TAH)" refers to the sum of the resolved aliphatic hydrocarbons (RAH) and UCM in both the particulate (P) and the dissolved (D) phases, expressed in $\mu \mathrm{g} \mathrm{L}^{-1}$. The median TAH levels of runoff samples, which sometimes varied from one rain to another by at least two orders of magnitude, underlining a great temporal variability, ranged from 297 to $1359 \mu \mathrm{g} \mathrm{L}^{-1}$. On the one hand, our data were in good agreement with previous studies carried out in urban areas. For example, the levels of hydrocarbons determined in Madrid city runoff, simulated by the mean of a hose pipe, were in the $412-1154 \mu \mathrm{g} \mathrm{L}^{-1}$ range [10]. Urban runoff was sampled at several points in residential, landscaped, commercial and industrial areas of Madrid with distinct traffic levels. In an urban catchment in London [12], dominated by storm water inputs from both combined and separate sewer systems, with $60 \%$ of the storm flow coming from surface runoff, the TAH levels varied between 360 and $1100 \mu \mathrm{g} \mathrm{L}^{-1}$. Hoffman et al. [16] found, in urban runoff from a commercial land use area, a similar range of concentration, i.e. 690$2150 \mu \mathrm{g} \mathrm{L}^{-1}$. On the other hand, PAH levels ranged from less than 1 to $215 \mathrm{ng} \mathrm{L}^{-1}$ according to the sampling site (Table 3); they represented less than $0.05 \%$ of the total hydrocarbon contents in the "Le Marais" catchment. Furthermore, there was no observed effect on the hydrocarbon concentrations of the length of the dry weather period following the last storm.

The particulate level of UCM found in this study ranged from 2231 up to $18495 \mu \mathrm{g} \mathrm{g}^{-1} \mathrm{dw}$ according to the sample location (Table 4). Bomboi and Hernandez 

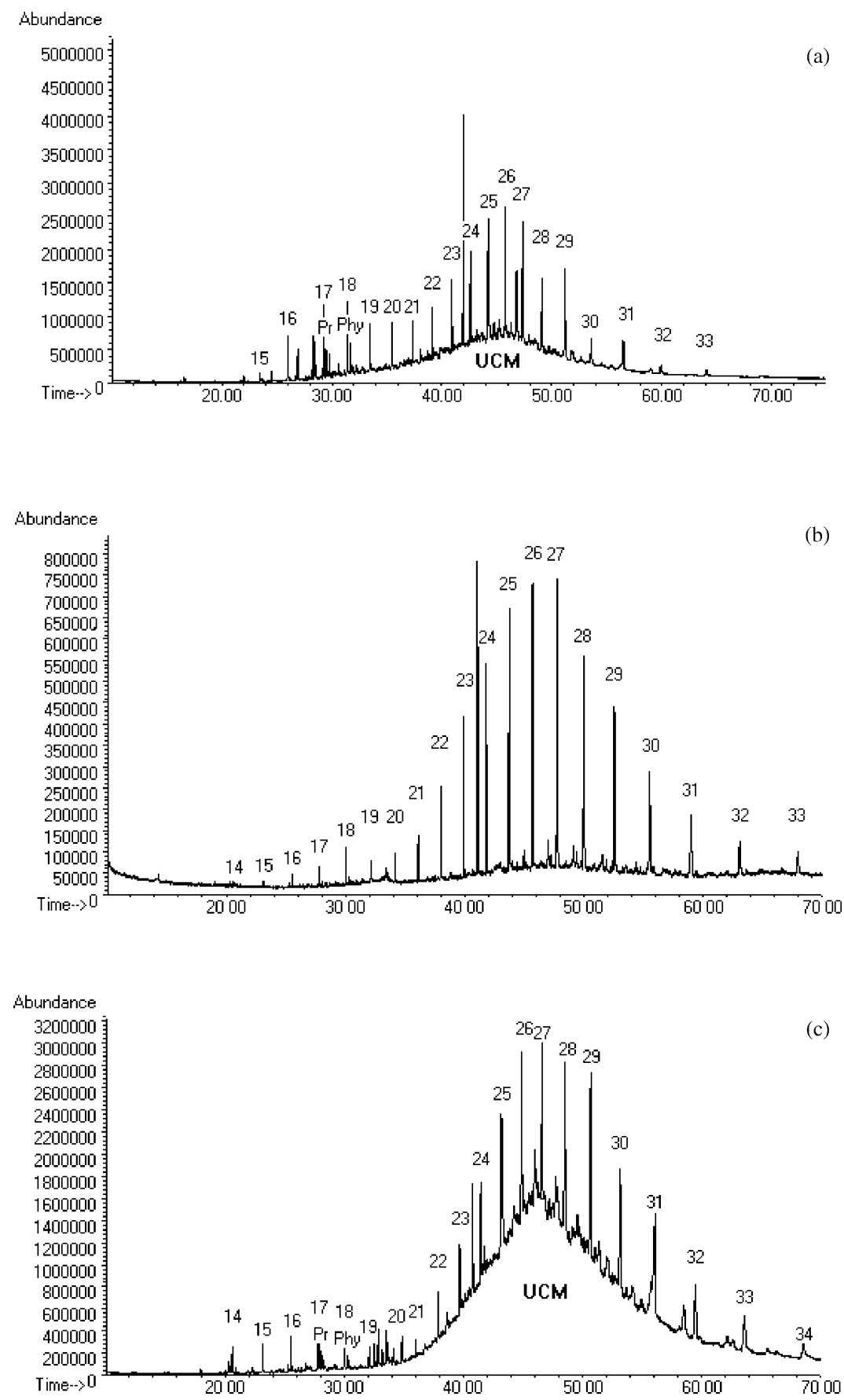

Fig. 3. Chromatograms of aliphatic hydrocarbons of urban runoff: (a) particulate fraction of the sewer outlet, (b) dissolved fraction of ST roof runoff, (c) particulate fraction of ST roof runoff. Numbers refer to the $n$-alkane series, Pr to pristane and Ph to phytane.

[10] reported values ranging from 20 to $8742 \mu \mathrm{gg}^{-1} \mathrm{dw}$ in urban runoff from Madrid. Despite this discrepancy, in both studies, the UCM constitutes the main part of the total content of aliphatic hydrocarbons in the
"Le Marais" and Madrid runoffs, i.e. $75 \%$ and $80 \%$, respectively. The distribution of resolved and unresolved hydrocarbons in particulate and dissolved phases confirms previous observations $[12,16]$, viz. hydrocarbons 
Table 3

Distribution of total aliphatic hydrocarbons (TAHs) between dissolved and particulate phases and the range of polycyclic aromatic hydrocarbon (PAHs) concentrations

\begin{tabular}{|c|c|c|c|c|c|c|c|c|c|c|c|c|c|c|c|c|}
\hline & \multirow[t]{2}{*}{$n$} & \multicolumn{3}{|c|}{ TAHs $\left(\mu \mathrm{g} \mathrm{L}^{-1}\right)$} & \multicolumn{3}{|c|}{ D RAHs $\left(\mu \mathrm{g} \mathrm{L}^{-1}\right)$} & \multicolumn{3}{|c|}{ P RAHs $\left(\mu \mathrm{g} \mathrm{L}^{-1}\right)$} & \multicolumn{3}{|c|}{ P UCM $\left(\mu \mathrm{g} \mathrm{L}^{-1}\right)$} & \multicolumn{3}{|c|}{ PAHs $\left(\operatorname{ng~L}^{-1}\right)^{\mathrm{a}}$} \\
\hline & & $\mathrm{d} 10$ & $\mathrm{~d} 50$ & $\mathrm{~d} 90$ & $\mathrm{~d} 10$ & $\mathrm{~d} 50$ & d90 & $\mathrm{d} 10$ & $\mathrm{~d} 50$ & $\mathrm{~d} 90$ & $\mathrm{~d} 10$ & $\mathrm{~d} 50$ & $\mathrm{~d} 90$ & $\mathrm{~d} 10$ & $\mathrm{~d} 50$ & $\mathrm{~d} 90$ \\
\hline \multicolumn{17}{|l|}{ Roofs } \\
\hline ICT & 19 & 130 & 345 & 1942 & 10 & 40 & 226 & 8 & 21 & 196 & 83 & 289 & 1752 & $<1$ & 24 & 724 \\
\hline FCT & 23 & 71 & 426 & 2561 & 13 & 78 & 221 & 5 & 35 & 277 & 46 & 251 & 1912 & $<1$ & 50 & 717 \\
\hline ST & 42 & 127 & 422 & 1733 & 9 & 73 & 247 & 6 & 27 & 219 & 99 & 288 & 1703 & $<1$ & 16 & 487 \\
\hline ZNT & 33 & 224 & 847 & 2327 & 47 & 118 & 141 & 26 & 66 & 510 & 130 & 579 & 1376 & $<1$ & 22 & 687 \\
\hline \multicolumn{17}{|c|}{ Courtyards } \\
\hline CONC & 9 & 290 & 790 & 3462 & 39 & 124 & 272 & 11 & 85 & 456 & 182 & 452 & 2974 & $<1$ & $<1$ & 2235 \\
\hline PAVC & 6 & 186 & 297 & 1541 & 9 & 38 & 114 & 6 & 26 & 445 & 138 & 200 & 1049 & $<1$ & 54 & 671 \\
\hline \multicolumn{17}{|l|}{ Streets } \\
\hline TUR & 11 & 267 & 813 & 3748 & 42 & 170 & 263 & 17 & 49 & 214 & 75 & 609 & 3053 & $<1$ & $<1$ & 375 \\
\hline DUV & 10 & 120 & 393 & 925 & 15 & 71 & 143 & 9 & 39 & 73 & 81 & 283 & 760 & $<1$ & 157 & 1382 \\
\hline VDT & 11 & 386 & 1359 & 4032 & 46 & 90 & 286 & 12 & 79 & 510 & 261 & 1155 & 3666 & 82 & 215 & 1114 \\
\hline \multicolumn{17}{|c|}{ Catchment outlet } \\
\hline CODW & 46 & 251 & 767 & 1989 & 13 & 35 & 294 & 14 & 78 & 306 & 149 & 558 & 1498 & $<1$ & $<1$ & 973 \\
\hline COWW & 19 & 318 & 704 & 2243 & 40 & 124 & 181 & 17 & 45 & 131 & 252 & 454 & 1955 & $<1$ & 66 & 877 \\
\hline
\end{tabular}

${ }^{\text {a }}$ From Gonzalez et al. [5].

Table 4

Range of particulate resolved (P RAHs) and unresolved (P UCM) aliphatic hydrocarbons, and polycyclic aromatic hydrocarbons (PAHs) concentration in suspended solids

\begin{tabular}{|c|c|c|c|c|c|c|c|c|c|c|}
\hline & \multirow[t]{2}{*}{$n$} & \multicolumn{3}{|c|}{ P RAHs $\left(\mu \mathrm{gg}^{-1} \mathrm{dw}\right)$} & \multicolumn{3}{|c|}{ P UCM $\left(\mu \mathrm{gg}^{-1} \mathrm{dw}\right)$} & \multicolumn{3}{|c|}{ PAHs $\left(\operatorname{ngg}^{-1} \mathrm{dw}\right)^{\mathrm{a}}$} \\
\hline & & $\mathrm{d} 10$ & $\mathrm{~d} 50$ & d 90 & $\mathrm{~d} 10$ & $\mathrm{~d} 50$ & d 90 & $\mathrm{~d} 10$ & $\mathrm{~d} 50$ & d90 \\
\hline \multicolumn{11}{|l|}{ Roofs } \\
\hline ICT & 19 & 261 & 689 & 6870 & 3813 & 9138 & 35672 & $<10$ & 800 & 11340 \\
\hline FCT & 23 & 153 & 993 & 14896 & 1481 & 7033 & 48756 & $<10$ & 2000 & 10240 \\
\hline ST & 42 & 176 & 1029 & 7031 & 2523 & 13531 & 68298 & $<10$ & 450 & 14310 \\
\hline ZNT & 33 & 885 & 2567 & 14595 & 3556 & 18495 & 45237 & $<10$ & 600 & 14040 \\
\hline \multicolumn{11}{|c|}{ Courtyards } \\
\hline CONC & 9 & 88 & 1228 & 6596 & 1780 & 7710 & 54824 & $<10$ & $<10$ & 24160 \\
\hline PAVC & 6 & 191 & 910 & 14234 & 2923 & 7042 & 36027 & $<10$ & 2000 & 10240 \\
\hline \multicolumn{11}{|l|}{ Streets } \\
\hline TUR & 11 & 216 & 483 & 4119 & 2079 & 5517 & 25400 & $<10$ & $<10$ & 8070 \\
\hline DUV & 10 & 158 & 434 & 898 & 1439 & 3051 & 6456 & $<10$ & 1600 & 15270 \\
\hline VDT & 11 & 198 & 582 & 9116 & 2386 & 7492 & 40999 & 600 & 4300 & 19900 \\
\hline \multicolumn{11}{|c|}{ Catchment outlet } \\
\hline CODW & 46 & 255 & 716 & 2713 & 1914 & 4452 & 10835 & $<10$ & $<10$ & 10270 \\
\hline COWW & 19 & 43 & 199 & 952 & 1281 & 2331 & 10335 & $<10$ & 200 & 5240 \\
\hline
\end{tabular}

\footnotetext{
${ }^{\mathrm{a}}$ From Gonzalez et al. [5].
}

are largely associated to particulate material at $85 \%$ for runoff. At the combined sewer outlet, they were in a particulate form at $80 \%$ during a rain event and at $95 \%$ during dry weather periods. At a greater extent, the same trend was observed for PAHs. They were found predominantly in the particulate phase [5]. The average 


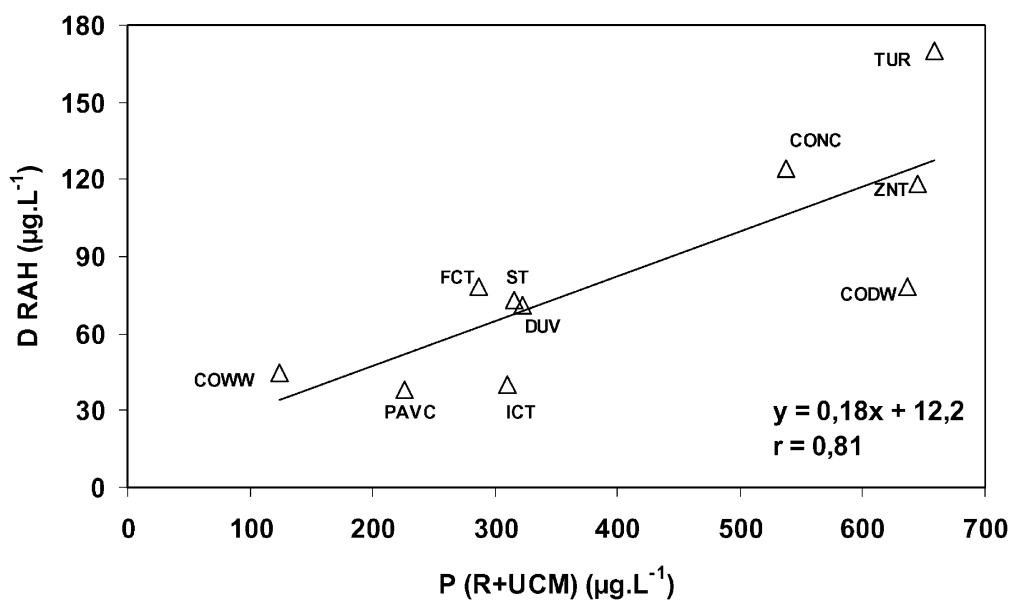

Fig. 4. Relationship between the dissolved resolved aliphatic hydrocarbons (D RAH) and the particulate resolved and unresolved aliphatic hydrocarbons (P R + UCM) during a storm event.

values of the particulate to the dissolved total hydrocarbon $(\mathrm{P} / \mathrm{D})$ ratio were $5 \pm 1.8$ for roof, $5 \pm 1.1$ for courtyard and $7 \pm 5.5$ for street runoff. This underlined quite a constant distribution of the hydrocarbons between dissolved and particulate phases throughout the entire catchment during a storm. Consequently, it is likely that the amount of dissolved hydrocarbons is directly proportional to the amount of hydrocarbons sorbed on the particulate material rather than to the SS concentration itself. Furthermore, the dissolved resolved aliphatic hydrocarbon amount (D RAH) had a good linear correlation with the particulate unresolved and resolved hydrocarbon amount $(\mathrm{P} \mathrm{UCM}+\mathrm{R})$, with a good correlation coefficient $(r=0.88)$, as shown in Fig. 4. In this figure, VDT was not considered due to its value of the $\mathrm{P} / \mathrm{D}$ ratio, i.e. 14 , due to a surprisingly higher content of P UCM than TUR and DUV samples.

For roof runoff samples, as previously noticed for PAHs [5] and SS in this paper, the spatial variability, i.e. among the different roofs, was smaller than the temporal variability (Table 3). Thus, the TAH concentrations were quite similar from one roof to another, except for the zinc covered roof (ZNT); the TAH levels ranged from $\approx 400 \mu \mathrm{g} \mathrm{L}^{-1}$ for ICT, FCT and ST to $847 \mu \mathrm{g} \mathrm{L}^{-1}$ for ZNT. The erosion of the roof material during a rain event did not explain these differences since the SS levels were of the same order of magnitude. Only the nature of the particles could explain these differences that there was a 2-4 fold increase in the TAH concentration for the zinc roof particles when compared to the other roof particles (Table 4). Since atmospheric deposition is the predominant mode of particle loading, as already mentioned for SS contents, and is assumed to be homogeneous all over the assessed area of $42 \mathrm{ha}$, it is likely that the TAH content for a given roof might be driven by the nature of the roof itself. A similar trend-physical and chemical features of the roof surfaces with a great influence on the concentration of organic trace pollutants in runoff-was observed for PAHs on four different roofs at the university of Bayreuth (Germany) [17]. In the "Le Marais" catchment, PAHs exhibited a different behaviour than aliphatic hydrocarbons. The highest concentration concerned that of FCT, with $50 \mathrm{ng} \mathrm{L}^{-1}$, whereas for the three remaining roofs the PAH contents were of the same order of magnitude, i.e. $20 \mathrm{ng} \mathrm{L}^{-1}$. Therefore, both the roof characteristics and the chemical properties of the organic pollutants should be taken into account in order to evaluate the level of pollution in runoff.

In the courtyard runoff samples, there was a significant $2-3$ fold increase in the TAH amount for the concrete courtyard, compared to the paved one, i.e. $790-297 \mu \mathrm{g} \mathrm{L}^{-1}$, respectively. Such a difference between both courtyard runoff samples was not surprising since the PAVC runoff contained more SS than the CONC (Fig. 2).

Regarding the street runoff, a spatial variation was observed. The median of the TAH concentrations ranged from $393 \mu \mathrm{g} \mathrm{L}^{-1}$ for DUV sample to $1359 \mu \mathrm{g} \mathrm{L}-1$ for VDT, with an intermediate value for TUR (i.e. $813 \mu \mathrm{g} \mathrm{L}^{-1}$ ). According to the characteristics of the different streets, where the samples were collected, intuitively, one should have expected higher TAH concentrations in the Turenne samples due to the presence of parking places along with a medium to heavy traffic density. These two factors contribute to the hydrocarbon pollution through either leaks from cars or via exhaust fumes [18]. In the Vieille du Temple gully, runoff came from streets with no parking places and a lower traffic density. Duval gully received runoff from 
streets with parking places but with a lower traffic compared to Turenne. Since SS contents were identical for the three gullies, i.e. $85 \mathrm{mg} \mathrm{L}^{-1}$, only the features of the particle explained these results. To conclude, the particulate hydrocarbon contents are site-dependent, but we have no explanation for this dependence with regard to the TAH contents measured in the different gully samples.

At the catchment outlet, the TAH concentrations were of the same order of magnitude, $700 \mu \mathrm{g} \mathrm{L}^{-1}$, in either case, i.e. dry or wet weather periods. However, as already mentioned, during a storm, an erosion of the sewer deposit occurred, increasing the SS contents of the waste waters flowing within the sewer. Meanwhile, the particles during dry weather periods were more contaminated than particles flowing during wet weather periods. Hence, the conjunction of both phenomenon leads to a misleading apparent equivalence between the TAH concentrations measured during dry and wet weather periods.

As previously noticed, UCM is more resistant to degradation than other less complex hydrocarbons such as the $n$-alkanes, therefore the degree of degradation of a hydrocarbon input can be assessed by comparing the relative amounts of the different groups of compounds. So the UCM-to-resolved $n$-alkane hydrocarbon ratio (UCM/RAH) was used as a diagnostic criterion of pollutant inputs in order to discriminate biogenic from petrogenic sources. A biogenic input is characterised by a ratio lower than 2, whereas higher values of this ratio indicate petrogenic origins. The presence of a higher proportion of unresolved material might suggest a greater degree of weathering of the hydrocarbon input in these samples as well [13]. The UCM/RAH ratio varied between 3 and 16 underlining the anthropogenic nature of the pollutant sources. Furthermore, the calculation of the carbon preference index (CPI, defined as the ratio of odd-to-even carbon numbered $n$-alkanes), whatever the location or the fraction, never gave CPI values greater than 1.5 . Therefore, this index confirmed the anthropogenic nature of the hydrocarbon sources in the "Le Marais" catchment, since CPI near 1.0 is usually found in the chain lengths typical to fossil hydrocarbon suites, while CPI values greater than 10 indicate a predominance of natural sources [19]. The use of three other indices, such as the $\mathrm{C}_{17} / \mathrm{Pr}$, $\mathrm{C}_{18} / \mathrm{Ph}$ and $\mathrm{Pr} / \mathrm{Ph}$ ratios, were useful to determine the degree of biodegradation of samples. High concentrations of pristane may be indicative of high levels of microbial degradation. In petroleum contaminated samples, the concentration of pristane and phytane are nearly equal [20]. In the particulate fraction, the $\mathrm{Pr} / \mathrm{Ph}$ ratios were near unity with average values of 1.0 , $0.9,0.6$ and 1.1, respectively, for roof, courtyard and street runoff and sewer outlet. Thus, the petrogenic origin seems to be highlighted by the use of this ratio, as well as the weak microbial degradation. The presence of pristane and phytane with relatively low values of $\mathrm{C}_{17} / \mathrm{Pr}$ and $\mathrm{C}_{18} / \mathrm{Ph}(<5)$ confirmed this weak microbial activity in runoff [21]. The values measured at the combined sewer outlet during a rain event showed the same trend. Organisms present in runoff have had an insufficient time to build up the enzymes necessary to degrade the hydrocarbons [12]. Moreover, in order to remove hydrocarbons from urban surfaces, evaporation and photo-oxidation were the most occurring processes compared to biodegradation during dry weather conditions [10].

Finally, with the knowledge of both the hydrocarbon concentrations and the rain intensity, the fluxes in term of mass per unit surface were calculated. Our results are summarised in Table 5. Hydrocarbon fluxes for roof were around $20 \mathrm{~g} \mathrm{ha}^{-1}$ and were quite constant for the four roof covering materials. Regarding the courtyard and street fluxes, our results were directly related to the hydrocarbon concentrations: the higher the concentration, the higher the flux. At the catchment outlet, during a storm, we noticed a four-fold increase of the hydrocarbon flux due to urban surface washoff and sewer sediment erosion. Hence, when the total mass loading of hydrocarbon was calculated at the scale of the whole catchment, it appeared that roof loading represented $51 \%$ of the total loading due to runoff, whereas street and courtyard loading contributed to $42 \%$ and $7 \%$, respectively. According to our results, about $48 \%$ and $75 \%$ of the TAH and

Table 5

Fluxes of total aliphatic hydrocarbons for the different runoff types

\begin{tabular}{lcccr}
\hline & Surface (ha) & \multicolumn{3}{c}{ TAHs $\left(\mathrm{g} \mathrm{ha}^{-1}\right)$} \\
\cline { 3 - 5 } & & $\mathrm{d} 10$ & $\mathrm{~d} 50$ & $\mathrm{~d} 90$ \\
\hline Roofs & 22 & & & \\
ICT & 2 & 6 & 24 & 175 \\
FCT & 2.5 & 6 & 24 & 109 \\
ST & 5 & 8 & 20 & 94 \\
ZNT & 12.4 & & & \\
& & & & \\
Courtyards & 5 & 19 & 49 & 314 \\
CONC & 1.1 & 7 & 13 & 156 \\
PAVC & 3.8 & & & \\
Streets & 9 & 17 & 64 & 173 \\
TUR & & 12 & 20 & 53 \\
DUV & & 16 & 67 & 409 \\
VDT & & & & \\
Catchment outlet & 42 & 7 & 15 & 30 \\
CODW & & 22 & 64 & 212 \\
COWW & & & & \\
\hline
\end{tabular}


PAH loading, respectively, originated from within the combined sewer through the resuspension of sewer sediments due to erosion.

\section{Conclusion}

The results obtained from the measurements of TAHs in urban runoff, at various locations of an experimental urban catchment, suggest that these contaminants were largely derived from anthropogenic petroleum sources. Therefore, emissions from vehicles along with atmospheric fallout constitute the main part of hydrocarbon productions. Discriminating both sources is quite difficult since particles from both origins are mixed in the runoff. In addition, the determination of the hydrocarbon loading at the catchment outlet shows that the main part of the wet weather pollution originates from the combined sewer itself. During a storm event, it is likely that a resuspension of sewer deposits will occur. However, these sewer deposits need to be generated from deposition during dry and wet weather periods. Therefore, a better knowledge of the fate of particles during dry weather periods is needed to better understand the predominant role of combined sewers as physical and chemical reactors.

Yet, it is difficult to argue whether our findings can be generalised because they are obviously related to the main features of the studied catchment. Thus, the next step of our work is to extend the surface of the catchment up to hundreds of hectares in Paris conurbation and to pay more attention to the dry weather periods. However, our results provide a complete overview of the total aliphatic hydrocarbon contents found in runoff samples collected in an urban environment.

\section{Acknowledgements}

This work was supported by the Water Agencies, the municipality of Paris, the Ile de France county, the Laboratoire Central des Ponts et Chaussées, the French Ministry of Research and the PIREN-Seine programme (CNRS GDR 1067).

\section{References}

[1] Broman D, Colmsjo A, Ganning B, Naf C, Zebuhr Y, Ostman C. Fingerprinting petroleum hydrocarbons in bottom sediment, plankton and sediment trap collected seston. Mar Pollut Bull 1987;18:380-8.

[2] Chebbo G. Solids in urban wet weather discharges: characteristics and treatability (in French: Solides des rejets pluviaux urbains. Caractérisation et traitabilité),
Ph.D. thesis, Ecole Nationale des Ponts et Chaussées, Paris, France, 410pp. + appendices, 1992.

[3] Xanthopoulos C, Hahn HH. Anthropogenic pollutants wash-off from street surfaces. Proceedings of Sixth International Conference on Urban Storm Drainage, Niagara Falls, Ontario, Canada, vol. 1, 1993. p. 417-22.

[4] Gromaire-Mertz MC, Garnaud S, Gonzalez A, Chebbo G. Characterisation of urban runoff pollution in Paris. Water Sci Technol 1999;39(2):1-8.

[5] Gonzalez A, Moilleron R, Chebbo G, Thévenot D. Determination of polycyclic aromatic hydrocarbons in urban runoff samples from the Le Marais experimental catchment in Paris centre. Polycyclic Aromat Compounds 2000;20:1-19.

[6] Gromaire-Mertz MC, Chebbo G, Saad M. Origins and characteristics of urban wet weather pollution in combined sewer systems: the experimental urban catchment Le Marais in Paris. Water Sci Technol 1998;37(1):35-43.

[7] Gonzalez A, Garnaud S, Carpentier S, Moilleron R, Thévenot DR. Significance of dissolved and particulate metal and hydrocarbon determination in urban runoff samples. Proceedings of Eighth International Conference on Urban Storm Drainage, Sydney, Australia, vol. 4, 1999. p. 1816-24.

[8] Hoffman EJ, Quinn JG. Chronic hydrocarbon discharges into aquatic environments: II-Urban runoff and combined sewer owerflows. Proceedings of the Oil in Freshwater Conference, Edmonton, Canada, 1984. p. 114-37.

[9] Xanthopoulos C, Hahn HH. Pollutants attached to particles from drainage areas. Sci Total Environ 1990;93:441-8.

[10] Bomboi MT, Hernandez A. Hydrocarbons in urban runoff: their contribution to waste waters. Water Res 1991;25(5):557-65.

[11] Förster J. Patterns of roof runoff contamination and their potential implications on practice and regulation of treatment and local infiltration. Water Sci Technol 1996;33(6):39-48.

[12] Gavens A, Revitt DM, Ellis JB. Hydrocarbon accumulation in freshwater sediments of an urban catchment. Hydrobiologia 1982;91:285-92.

[13] Aboul-Kasim TAT, Simoneit BRT. Lipid geochemistry of surficial sediments from the coastal environment of Egypt. I. Aliphatic hydrocarbons - characterization and sources. Mar Chem 1996;54:135-58.

[14] Gough MA, Rowland SJ. Characterization of unresolved complex mixtures of hydrocarbons in petroleum. Nature 1990;344:648-50.

[15] Gough MA, Rhead MM, Rowland SJ. Biodegradation studies of unresolved complex mixtures of hydrocarbons: model UCM hydrocarbons and aliphatic UCM. Org Geochem 1992;18:17-22.

[16] Hoffman EJ, Latimer JS, Mills GL, Quinn JG. Petroleum hydrocarbons in urban runoff from a commercial land use area. J Water Pollut Control Fed 1982;54(11):1517-25.

[17] Daub J, Förster J, Herrmann R, Robien A, Striebel T. Chemodynamics of trace pollutants during snowmelt on roof and street surfaces. Water Sci Technol 1994;30(1):73-85.

[18] Xanthopoulos C, Hahn HH. Sources of pollution of stormwater runoff from urban areas. Novatech 92 Analysis and Modelisation, 1992. p. 43-53. 
[19] Kawamura K, Kaplan IR. Biogenic and anthropogenic organic compounds in rain and snow samples collected in southern California. Atmos Environ 1986;20:115-24.

[20] Gearing P, Gearing JP, Lytle TF, Lytle JS. Hydrocarbons in 60 northeast Gulf of Mexico shelf sediments: a preliminary survey. Geochim Cosmochim Acta 1976;40: 1005-17.
[21] Colombo JC, Pelletier E, Brochu C, Khalil M, Catoggio JA. Determination of hydrocarbon sources using $n$-alkane and polyaromatic hydrocarbon distribution indexes. Case study: Rio de La Plata Estuary, Argentina. Environ Sci Technol 1989;23:888-94. 